\title{
O impacto da hospitalização infantil nas rotinas das famílias monoparentais*
}

\author{
The impact of child hospitalization on the everyday lives of single parent families
}

Impacto de la internación infantil en las rutinas de las familias monoparentales

Pamela Camila Fernandes Rumor ${ }^{1}$, Astrid Eggert Boehs ${ }^{2}$

\footnotetext{
* Artigo elaborado a partir de um recorte dos resultados da dissertação, intitulada "O impacto da hospitalização infantil nas rotinas de cuidado das famílias monoparentais", defendida em 2012, vinculada a Universidade Federal de Santa Catarina.

${ }^{1}$ Enfermeira, Mestre em Enfermagem. Chefe do Serviço de Enfermagem da Clínica Cirúrgica 1 do Hospital Universitário da Universidade Federal de Santa Catarina (UFSC). Florianópolis, SC, Brasil. E-mail: pamrumor@hotmail.com.

${ }^{2}$ Enfermeira, Doutora em Enfermagem. Professora Associada da UFSC. Florianópolis, SC, Brasil. E-mail: astridboehs@hotmail.com.
}

\section{RESUMO}

Pesquisa descritiva de abordagem qualitativa realizada em uma unidade de internação pediátrica com o objetivo de compreender o impacto da hospitalização infantil nas rotinas das famílias monoparentais. Foram entrevistadas 12 famílias, representadas pelas mães, através de um formulário dividido em duas partes: construção do genograma e ecomapa e questões semiestruturadas. Foi usado o método de análise de conteúdo. Os resultados apontam que a dependência da rede de apoio familiar e a dificuldade de um olhar individualizado para as diferentes formas de família por parte dos profissionais e das instituições para atenderem às demandas das famílias são os principais fatores que causam o impacto nas rotinas diárias das famílias monoparentais. Conclui-se que há necessidade de uma reflexão e revisão das práticas e normas institucionais visando ao atendimento das reais peculiaridades e necessidades do cotidiano das famílias contemporâneas.

Descritores: Família de Pais Solteiros; Criança Hospitalizada; Enfermagem Familiar.

\section{ABSTRACT}

This qualitative descriptive study was performed at a pediatric hospitalization unit with the objective to understand the impact of child hospitalization on the daily lives of single parent families. Interviews were conducted with twelve families, represented by the mothers, using a form divided into two parts: construction of the genogram and ecomap and semi-structured questions. Content analysis was used. The results point out that the major factors affecting the everyday lives of single parent families is the dependency on the family support network and the difficulty that both healthcare professionals and institutions have in developing an individualized look at the different family structures when providing their needs. In conclusion, there is a need for thinking and reviewing institutional practices and norms aiming at meeting the true particularities and needs of the everyday lives of today's families.

Descriptors: Single-Parent Family; Child, Hospitalized; Family Nursing.

\section{RESUMEN}

Investigación descriptiva de abordaje cualitativo, realizada en unidad de internación pediátrica, objetivando comprender el impacto de la internación infantil en las rutinas de familias monoparentales. Fueron entrevistadas 12 familias, representadas por las madres, mediante formulario dividido en dos partes: construcción del genograma y ecomapa, y preguntas semiestructuradas. Se utilizó el método de análisis de contenido. Los resultados expresan que la dependencia de la red de apoyo familiar y la dificultad de una visión individualizada para los diferentes modelos de familia por parta de los profesionales y de las instituciones para atender la demanda de las familias son los principales factores que impactan en las rutinas diarias de las familias monoparentales. Se concluye en que existe necesidad de reflexión y revisión de prácticas y normas institucionales, apuntando a la atención de las auténticas peculiaridades y necesidades cotidianas de las familias contemporáneas.

Descriptores: Familia de Padres Solteros; Niño Hospitalizado; Enfermería de la Familia. 


\section{INTRODUÇÃO}

As mudanças sociais têm redefinido progressivamente os laços familiares(1), sendo que a família contemporânea é caracterizada por diversos arranjos, dentre eles o monoparental. Esta organização familiar, geralmente matrifocal, ou seja, chefiada por mulheres, vem crescendo estatisticamente em todos os segmentos da população e cada vez mais está presente nos serviços de saúde.

O termo família monoparental é compreendido pela entidade familiar em que o lar está sob a responsabilidade de apenas um dos pais e seus descendentes ${ }^{(2)}$. Este núcleo familiar é motivo de preocupação social, pois está sujeito a enfrentar inúmeras fragilidades e susceptibilidades, devido às dificuldades econômicas, tensão emocional, sobrecarga de responsabilidade e desvantagens sociais, nas quais as crianças podem ser as principais afetadas ${ }^{(1,3)}$. Portanto, a diversidade dos aspectos que envolvem o contexto familiar monoparental, assim como os inúmeros desafios que atingem a vida deste núcleo, ressalta que é preciso conhecer a sua realidade.

Na família, as ações, interações e processos dos seus diferentes membros buscam organizar a vida coletiva diária, ao estabelecer rotinas, distribuir tarefas e administrar os recursos de acordo com a situação em que estes se encontram(4). Ela desenvolve complexas estratégias para a manutenção da saúde e a continuidade da vida. A investigação baseada na abordagem das rotinas das famílias permite detectar os papéis familiares e os modos como estas organizam suas práticas de cuidado, tanto nas situações de saúde como de doença(5). No âmbito da enfermagem, a pioneira neste tema foi a norteamericana Sharon Denham ${ }^{(4)}$, que buscou aproximar este referencial ao cuidado da saúde das famílias. Ela conceituou as rotinas como comportamentos estreitamente ligados às atividades diárias e regulares, os quais mudam conforme as interações e necessidades da unidade familiar ao longo do ciclo de vida.

Na literatura nacional, os estudos desenvolvidos que investigaram as rotinas das famílias com crianças lactentes cujas mães trabalhavam para o sustento da família ${ }^{(5)}$, as rotinas de famílias com crianças desnutridas ou em risco nutricional, participantes de um Programa de Suplementação Alimentar ${ }^{(6)}$, as rotinas de famílias que vivem em uma comunidade ribeirinha amazônica, tendo como característica principal o isolamento geográfico e social(7) e as rotinas e rituais de cuidado nas famílias rurais com criança em transição inesperada do pós-desastre natural ${ }^{(8)}$. Com fundamento nestes estudos, verifica-se que a abordagem das rotinas familiares se aplica a diferentes realidades de saúde e variados contextos culturais em que a enfermagem possa estar atuando com famílias.

No ciclo de desenvolvimento das famílias ocorrem eventos inesperados que podem interferir na organização do cotidiano e da rotina familiar, como por exemplo, a hospitalização de um membro, especialmente quando se trata de uma criança. A complexidade dos aspectos que envolvem a hospitalização infantil tem sido amplamente discutida(9-19), evidenciando que as famílias têm dificuldades em lidar com os desafios trazidos pelo enfrentamento dessa situação, as quais podem estar acentuadas quando se trata de um núcleo monoparental.

Quando um membro da família se afasta de suas atividades rotineiras, ocorrem mudanças na estrutura interna e externa da família, já que o membro doente passa a ser prioridade no cuidado familiar e os pais ausentam-se do lar, dos cuidados dos outros filhos e dos afazeres domésticos $^{(9,11)}$. Aliado a isso, o acompanhante, geralmente a mãe, também passa por período de inadequação ao ambiente, pois precisa enfrentar o diagnóstico, vivenciar sentimentos e angústias, adaptarse a um cenário hostil e às normas hospitalares, conviver com outras experiências de sofrimento, além de ter preocupações existentes ao ter a vida familiar dividida entre a casa e o hospital ${ }^{(11,18)}$.

Nesta perspectiva, no cotidiano do trabalho no hospital, torna-se imprescindível ampliar o foco para além do cuidado integral à criança, e voltar à atenção também às necessidades das famílias ${ }^{(10,14)}$. Para isso, é preciso que os profissionais considerem em sua prática, a diversidade das dinâmicas familiares, a complexidade das dimensões envolvidas na vida destas, e a realidade socioeconômica e cultural em que elas vivem. A partir das considerações apresentadas, pergunta-se: Qual o impacto da hospitalização infantil nas rotinas das famílias monoparentais? Este estudo objetiva compreender o impacto da hospitalização infantil nas rotinas das famílias monoparentais.

$\mathrm{Na}$ intenção de contribuir com elementos teóricos à prática de enfermagem, a realização desta pesquisa se justifica pelo fato de que a compreensão do impacto da 
hospitalização infantil nas rotinas das famílias monoparentais, favorecerá o planejamento de intervenções sensíveis tanto às particularidades como ao potencial de cada família e oferecerá subsídios para a construção de políticas institucionais pautadas na realidade dos sujeitos a serem cuidados, contribuindo para o avanço da humanização da assistência.

\section{METODOLOGIA}

Trata-se de uma pesquisa descritiva de abordagem qualitativa. O estudo foi realizado na unidade de internação pediátrica (UIP) de um hospital público do Sul do país, a qual possui 30 leitos, distribuídos em áreas específicas, com vagas para crianças em faixa etária de lactentes, pré-escolares e escolares. Destes, cinco leitos são vinculados à emergência pediátrica e servem para observação por 24 horas, de crianças cujas condições de saúde podem ser revertidas em menor tempo de permanência no hospital. No setor, trabalha uma equipe interdisciplinar de saúde e, durante a internação, um acompanhante (responsável) permanece junto à criança.

Participaram do estudo 12 mães que acompanharam seus filhos internados na UIP e atenderam aos seguintes critérios de inclusão: a) a família da criança deve ser monoparental matrifocal; b) a permanência da internação hospitalar deve ser de no mínimo dois dias; c) a hospitalização deve ser decorrente de uma doença aguda; d) a idade da criança deve ser inferior a sseis anos; e) residir na região metropolitana de Florianópolis.

Os dados foram coletados por meio de entrevistas realizadas no período de março a outubro de 2011. O instrumento de coleta de dados foi constituído por um roteiro semiestruturado composto por questões abertas e fechadas, dividido em três partes. A primeira, referente à caracterização sociodemográfica dos pacientes e informantes; a segunda, com o intuito de conhecer os membros da família monoparental e suas redes de suporte social através da construção do genograma e ecomapa; e a última, composta por questões amplas e abertas, cuja finalidade era a abordagem da temática central do estudo. Assim, as mães acompanhantes foram questionadas sobre a organização das rotinas familiares durante a hospitalização infantil. As entrevistas foram gravadas mediante permissão e, quando isso não era possível, os registros eram feitos imediatamente depois de finalizada a entrevista, procurando-se manter, na íntegra, as falas das entrevistadas.

Рara a análise dos dados referentes ao genograma, analisaram-se a composição e a estrutura familiar e, ao ecomapa, as redes de relações mais amplas estabelecidas pelos membros da família(20) para ajudar a identificar as rotinas de cada uma. Quanto aos dados qualitativos, foram examinados com base nos pressupostos da análise de conteúdo, seguidas as seguintes etapas: organização dos dados, codificação, categorização, inferências e interpretação(21). Após a transcrição das entrevistas, realizou-se leitura repetida e exaustiva, permitindo assim a ordenação do conjunto dos dados obtidos. Iniciou-se, desta forma, uma primeira classificação para apreender as estruturas relevantes, possibilitando o desvelamento das categorias empíricas confrontadas à luz do referencial teórico e da literatura atual.

O desenvolvimento do estudo ocorreu em conformidade com o preconizado pela Resolução N. ${ }^{\circ}$ 196/96 do Conselho Nacional de Saúde - MS e o projeto de pesquisa foi aprovado pelo Comitê de Ética em Pesquisa Envolvendo Seres Humanos da Universidade Federal de Santa Catarina (UFSC), sob o parecer N. ${ }^{\circ}$ 1191/2010. Todos os participantes foram informados sobre os objetivos do estudo, tipo de participação desejada, livre opção de aceitar participar sem qualquer prejuízo na assistência prestada à criança e, após concordância, assinaram o TCLE em duas vias. O nome da instituição foi mantido em sigilo e o anonimato das participantes foi resguardado. As participantes foram identificadas pela letra $F$, referente à palavra família, seguido de um algarismo arábico (ex.: F1; F2...).

\section{RESULTADOS E DISCUSSÃO}

\section{Características da estrutura familiar e do apoio social interno e externo}

A partir dos dados de identificação e dos genogramas, foi possível analisar a estrutura das famílias monoparentais entrevistadas.

As mães possuem idade de 19 a 34 anos, nove têm naturalidade na região metropolitana onde ocorreu o estudo, três são de outras cidades e/ou estados. Residem em moradias localizadas em regiões periféricas, sendo que cinco delas possuem casa própria, uma é alugada, quatro moram com os pais, duas possuem casa emprestada e todas afirmam ter acesso à energia elétrica 
e água encanada. O grau de escolaridade delas varia entre o ensino fundamental e o médio. Apenas uma mãe possui nível superior completo. No que diz respeito ao estado civil, somente uma considera-se divorciada, as demais se denominam solteiras. Sobre o tipo de ocupação, três trabalham em funções de limpeza no domicílio de famílias ou em estabelecimentos comerciais, quatro com serviços relacionados à copa e cozinha, uma como professora da rede pública, uma como estocadora de materiais, sendo que mais da metade apresenta vínculo empregatício formal, com registro na carteira profissional.

As crianças hospitalizadas tinham idade entre três meses e quatro anos, sendo nove do sexo masculino e três do feminino, nascidos na região metropolitana onde o estudo foi realizado e internados em decorrência de doença de origem aguda, conforme critério de seleção das famílias. A principal causa de hospitalização incidiu nas doenças respiratórias (bronquiolite, pneumonia, bronquite), manifestadas em nove crianças, as outras três internaram devido a estomatite, dermatite e anemia. 0 tempo médio da internação atual foi de aproximadamente cinco dias, em decorrência principalmente da antibioticoterapia endovenosa. Somente cinco crianças possuíam hospitalização prévia e uma apresentava atraso vacinal.

Em relação ao ecomapa, a análise dos dados possibilitou verificar a rede de suporte social e de relações das famílias monoparentais. Constatou-se a relevância do apoio dos familiares, de amigos, de vizinhos, que geralmente moram próximos, para a manutenção da rotina diária em nove núcleos monoparentais. O apoio concerne principalmente ao cuidado diário aos membros infantis, seja remunerado ou não, e também com recursos financeiros. Apenas uma família mora distante de sua família ampliada. Destaca-se a pouca participação dos membros do gênero masculino no suporte a tais famílias. Os três núcleos monoparentais que tinham menos apoio familiar, informaram que possuem como principal fonte de apoio o extrafamiliar, com destaque para as instituições de cunho educacional, social e de saúde, porém, todas as famílias entrevistadas recebem algum tipo de auxílio destes recursos.

No tocante ao suporte educacional, as creches públicas e privadas e os cuidadores são citados como recursos. Além disso, uma família possui relação próxima com outra instituição governamental, que desenvolve um projeto de cunho educacional e social, no qual as crianças desenvolvem atividades no período oposto ao turno escolar. Em relação à fonte de apoio à saúde, são mencionadas as unidades de saúde do bairro e hospitais da região metropolitana onde residem. A igreja da comunidade é frequentada semanalmente e recebem ajuda seja através de orações ou doações. Quanto às fontes de recursos financeiros, enfatiza-se a importância do trabalho remunerado da mãe. Para nove famílias, esta é a principal fonte de renda, no entanto, seis mães estão cumprindo o período de experiência no atual emprego, isto é, o tempo de trabalho é recente, menos de três meses. Outra relevante fonte é o benefício do Programa Bolsa Família, oriundo do Governo Federal, do qual apenas cinco famílias dizem receber este auxílio. Destacase, que das 12 mães entrevistadas, apenas uma recebia a pensão alimentícia do ex-marido.

\section{O impacto da hospitalização infantil nas rotinas diárias}

$\mathrm{Na}$ análise das respostas relacionadas ao impacto da hospitalização infantil nas rotinas diárias, emergiram três categorias: afastamento do lar e do cuidado aos membros familiares; hospitalização e seus reflexos à sobrecarga materna; preocupação com o retorno à rotina doméstica, as quais estão ligadas ao domicílio, ao hospital e à alta hospitalar, respectivamente.

Domicílio: afastamento do lar e do cuidado aos membros familiares

Esta categoria apresenta os resultados referentes ao impacto nas rotinas da família monoparental ligadas ao domicílio, sendo possível identificar duas subcategorias: distanciamento e contato limitado entre os familiares e reorganização da rotina familiar.

As mães vêem-se obrigadas a interromper as atividades domésticas e laborais para cuidar de um filho hospitalizado. No entanto, sabem que as outras responsabilidades, principalmente com relação aos outros filhos, demandam a sua atenção, o que gera um sentimento de impotência e motivo de sofrimento:

Minha irmã que está cuidando dos meus filhos. Eles estão indo pro projeto pela manhã e para a escola à tarde. Vou um dia sim e outro não ver meus outros filhos, pois se não estão vendo a mãe o que vão acabar pensando, que estão sem mãe também (F6). 
Meus outros filhos minha irmã e o meu padrinho estão cuidando. Eles vão para creche e ela cuida deles pra mim. Mas, fico preocupada de como eles estão (F3).

Sinto saudade da minha outra filha, ela está com a minha vizinha e o pai dela já foi lá ver ela também. Mas eu ligo e ela pergunta quando eu vou voltar para casa, aí eu explico que a mana está dodói e que a mãe tem que ficar com ela no hospital (F10).

A realidade de ter um filho hospitalizado, em sua condição de enfermo, desestrutura todo o cotidiano familiar, a começar por suas rotinas, pela ampliação de suas responsabilidades e pelo sofrimento gerado devido à convivência limitada, tanto pelas próprias condições da família quanto pelas impostas pelo hospital ou mesmo a patologia da criança(16).

Dessa forma, devido à ausência paterna, a monoparentalidade feminina implica na busca por alternativas para o enfrentamento desta situação e para a reorganização da rotina familiar, e encontram nos familiares a fonte de apoio necessária. Toda a família ampliada envolve-se no cuidar da casa e dos filhos da mãe acompanhante, sendo um auxílio efetivo, que ajuda a minimizar as preocupações da mãe ${ }^{(18)}$ :

Minha filha mais velha e a minha mãe estão me ajudando, cuidando da casa, lavando as roupas. Minha filha veio me visitar e eu também fui em casa para ver como estavam as coisas (F8).

Minha mãe que está cuidando deles, fazendo a comida, mandando eles para escola, lavando a roupa. Fui até em casa ontem para levar um pouco de roupa para lavar e para buscar outras coisas que precisava (F9).

A vizinha leva ela pra dormir na casa dela. Ela vai lá em casa e pega as coisas dela, o que ela gosta de comer, os brinquedos, as roupas (F10).

Somente uma mãe entrevistada não pode contar com o apoio familiar por residirem em estado diferente da família de origem, precisando recorrer a outras formas de apoio, neste caso à cuidadora particular.

Verifica-se que apesar de manter algumas rotinas existentes antes da hospitalização e de desejar retomar seu cotidiano, as famílias buscam se reestruturar, realizando mudanças de papéis, de relações entre si e com sua rede e revendo prioridades para atender às novas necessidades. Este movimento de retorno à estabilidade corrobora o argumento de que famílias precisam de ambientes domésticos organizados e estruturados para enfrentar as situações adversas que ocorrem no ciclo de vida familiar. A previsibilidade e a regularidade das rotinas familiares são capazes de fomentar a noção de permanência e de continuidade entre seus membros ${ }^{(22)}$.

Hospitalização e seus reflexos à sobrecarga materna

Esta categoria descreve o impacto nas rotinas da família monoparental no ambiente hospitalar e está relacionada com duas subcategorias: as várias tarefas maternas e a dificuldade para a manutenção das necessidades humanas básicas.

Com respeito às várias tarefas maternas, identificou-se que a mãe, além de assumir o papel de acompanhante, mantém a função de principal cuidadora da criança. Muitas relataram a preferência em permanecer como acompanhante do filho, por responsabilizarem-se com o estado de saúde e por acreditarem que a sua presença traz segurança para a criança, sendo fundamental para o seu conforto e recuperação. Dessa forma, apesar dos sentimentos que experiência acompanhando o filho internado, o estar com a criança permite-lhe apreciar adequadamente esta situação(14):

Eu não quero outra pessoa cuidando dela, quero estar aqui para saber o que está acontecendo, a evolução dela, eu me importo com ela (F10).

Por outro lado, algumas mães relataram que permanecem como acompanhantes em período integral pelo fato de não ter com quem dividir esta responsabilidade, seja devido à ausência da figura paterna ou pelo fato de os demais familiares possuírem outras atribuições:

A madrinha dele veio visitar e ficou com ele pra eu ir até em casa. Ela é minha prima, mas não tem como ficar muito tempo porque ela trabalha e tem os filhos dela pra cuidar também (F9).

No tocante à função de cuidadora, papel culturalmente atribuído à figura feminina, faz com que a mãe, mesmo no ambiente hospitalar, considere-se a 
responsável em manter os cuidados básicos à criança, como de higiene, alimentação, sono e repouso. As mães conhecem a divisão de tarefas e a rotina preconizada dentro da unidade de internação, sabem que a enfermagem realiza apenas os cuidados à criança considerados técnicos e/ou de maior complexidade:

Eu mesma cuido dele, dou o banho, troco as fraldas, dou a alimentação que eles trazem pronta. Elas (as enfermeiras) só fazem a medicação. Não tem como ter outro acompanhante (F4).

Aqui no hospital quem dá o banho, a comida e troca as fraldas sou eu. As enfermeiras cuidam do oxigênio e do soro, porque ele está tomando antibiótico (F5).

A literatura menciona que, com relação à organização do trabalho, a presença da família no hospital é compreendida também como recursos humanos auxiliares, sendo um agente facilitador do trabalho da equipe de enfermagem ${ }^{(10,17)}$. O cuidado, que antes era prestado apenas pela equipe de enfermagem, tem sido compartilhado com a família ou, muitas vezes, delegado a esta, caracterizando um processo de desresponsabilização da equipe ${ }^{(10)}$. Essa visão utilitarista sobre a família compromete o processo de cuidar, pois passa a ser considerada como ferramenta no cuidado e não como sujeito que precisa ser atendido em suas necessidades $^{(17)}$.

A mãe passa a dedicar-se ao cuidado da criança, procurando atender às necessidades do filho em detrimento das suas, revelando a outra sobrecarga enfrentada: a dificuldade para a manutenção das necessidades humanas básicas, que possibilitou verificar como a hospitalização interfere no estado emocional e físico das acompanhantes. Referiram o cansaço físico devido às condições das acomodações físicas e ao estranhamento em relação à alimentação fornecida pelo hospital.

Durante o processo de internação, os familiares podem mostrar-se vulneráveis, cansados física e psicologicamente. Muitas vezes, a mãe não identifica em seu círculo uma pessoa em que ela confie, e que considere como sendo tão dedicada e capaz quanto ela. Desta forma, mobiliza-se a favor da criança, procurando atender as necessidades do filho em detrimento das suas ${ }^{(13-14)}$.
O cansaço físico é decorrente, sobretudo da falta de infraestrutura do serviço, pois o hospital, em sua maioria, não dispõe de recursos físicos e funcionais que contribuam para a permanência do familiar neste ambiente. Já o desgaste psicológico é relacionado ao sentimento de culpa pelo adoecimento e hospitalização, ao isolamento do convívio social e familiar, à ansiedade e medo pelo desconhecido, e às dúvidas a respeito da situação de saúde da criança(14).

Assim, é possível inferir que, no mundo do hospital a genitora convive com normas e rotinas, muitas vezes rígidas, que se sobrepõem às rotinas de cuidado individual e da família, rompendo bruscamente com o seu modo de viver ${ }^{(14)}$. Portanto, mesmo com o ingresso formal da família no hospital, ainda não se avançou efetivamente na construção de um projeto terapêutico centrado na criança e sua família no hospital(10). A prática assistencial continua centrada nas ações técnicas ${ }^{(17)}$, sendo que a equipe multiprofissional, sobretudo a enfermagem, não está preparada para atender às demandas das famílias, principalmente as suas peculiaridades.

Alta hospitalar: preocupação com o retorno à rotina doméstica

Esta categoria mostra que, em sua rotina diária, a família continua com as responsabilidades e atividades anteriores, que são acrescidas às demandas decorrentes da hospitalização, relacionando-a às subcategorias: o medo de perder o emprego, a manutenção da vaga da criança na creche e as necessidades de mudanças das rotinas diárias.

Na condição da monoparentalidade, a maioria das participantes deste estudo precisa garantir o sustento da família e, para isto, trabalhar fora do lar. Assim, identificase a subcategoria o medo de perder o emprego. Esta preocupação foi manifestada de forma recorrente e com ênfase por quase todas as mães. Tal medo surge pela hospitalização inesperada do filho, e ainda por não terem outras pessoas com quem pudessem dividir a tarefa de cuidador e, mesmo pela opção de quererem permanecer como acompanhantes, a maioria precisa faltar ao trabalho.

O medo de perder o emprego leva estas mães a tomarem providências para comunicar aos empregadores o motivo da falta. Contudo, a simples comunicação não é 
suficiente, há ainda as que necessitam justificar formalmente a ausência no trabalho, portanto buscam recursos:

Eu tentei avisar para a minha patroa que eu estou no hospital. Ela sabe que ele estava doente porque tive que sair cedo do serviço porque a creche ligou. Mas, tentei ligar para avisar que ele está internado e o celular dela cai na caixa postal (F3).

Na escola onde eu trabalho a diretora pediu para eu levar o atestado médico e uma declaração que a minha filha esteva internada (F8).

Porém, mesmo diante da lei que assegura que a criança permaneça com um acompanhante e que este tem direito de receber um atestado, ainda muitas sofrem ameaças pelos empregadores, devido ao fato de o trabalho ser informal ou pelo pouco tempo de serviço no atual emprego.

O adoecimento agudo da criança atrelado à preocupação materna em permanecer no emprego estão associados a outras demandas das famílias monoparentais: a de manter a vaga da criança na creche, sendo que as mães também buscam formas para informar e justificar às instituições o motivo da falta da criança; e a apreensão com o estado de saúde do filho após a alta hospitalar, uma vez que ambas podem interferir no retorno às rotinas diárias, bloqueando o retorno ao trabalho materno e às atividades educacionais infantis.

Portanto, é inegável que quando se trata de famílias de baixa renda, a monoparentalidade pode ser uma dificuldade a mais que sobrecarrega a figura feminina, pois a mulher precisa assumir entre o trabalho remunerado, o cuidado com os filhos e a atividade doméstica. A rotina da mulher chefe de família encontra na mão-dupla trabalho/vida familiar, uma problemática que acaba por se refletir na participação dessa mulher na vida e formação de seus filhos, pois há dificuldade da mulher/mãe e provedora em promover o sustento da família e preservar uma participação mais efetiva junto a seus filhos e ao ambiente familiar ${ }^{(1,14)}$.

Algumas transições requerem maior reorganização da vida familiar, ou seja, com o advento do adoecimento e da hospitalização, as mães identificaram necessidades de mudanças nas rotinas diárias da família após a alta hospitalar. Esta consciência da necessidade de mudança é resultado de orientações recebidas pelos profissionais da equipe multiprofissional: enfermeiras, médicos, assistentes sociais que atenderam à família durante a internação infantil. Tais necessidades eram relacionadas à manutenção da saúde da criança e aos encaminhamentos para o recebimento dos direitos de pensão alimentícia e de benefícios sócio-governamentais.

O conjunto das três categorias que emergiram do estudo na perspectiva das rotinas familiares mostra que as principais responsáveis pelo papel de cuidadoras das crianças são as mães contando, sobretudo, com o apoio da rede feminina da família. Pelo fato de pertencerem a um núcleo monoparental, elas têm este apoio também fragilizado, já que os membros da família ampliada possuem outros compromissos como, cuidados com outros membros e emprego. O suporte externo é muito tênue, o que foi mostrado pela preocupação de perder o emprego e a vaga da criança na creche, além de muitas mães deste estudo não contarem com o auxilio financeiro governamental e a pensão do pai da criança. Isso demonstra que, mesmo se tratando de um período relativamente curto, tendo em vista que a hospitalização ocorre por causa aguda, as preocupações se multiplicam para estas mães provedoras e cuidadoras.

Retomando o referencial das rotinas das rotinas, é importante focar que algum grau de regularidade comportamental é uma característica quase universal das famílias e que a continuidade para o atendimento das necessidades dos membros representa uma dimensão crítica na ligação entre a experiência social e a saúde, pois as rotinas familiares são um importante recurso comportamental, mediante o qual, o estresse das mudanças de vida é absorvido(22). Assim, constatam-se nos dados deste estudo, que há um impacto considerável nas famílias monoparentais que vivenciam a hospitalização de uma criança, alterando as rotinas habituais. A ruptura das rotinas interfere na organização familiar, tornando a experiência da criança e família imprevisível.

Estas três categorias também apontam que ainda está muito presente na cultura brasileira a naturalização do cuidado da criança pelas mulheres/mães, mesmo que elas não possam sequer atender suas próprias necessidades básicas. Esta naturalização se reflete nas próprias falas das entrevistadas quando referem que fazem questão de elas próprias cuidarem dos seus filhos. 
As instituições e a categoria da enfermagem auxiliam a manter tais valores, quando não negociam com as mães os cuidados. As instituições hospitalares, ao se valerem do Estatuto da Criança e do Adolescente, encontraram uma forma de, por um lado, beneficiar a criança sem, no entanto, mudar também a forma de atender as peculiaridades dos diferentes arranjos familiares e de refletir que estas mulheres precisam de apoio para o cuidado da criança, mas também ser alvo deste cuidado. Esta falta de reflexão, como já apontada em outro estudo ${ }^{(5)}$, leva à imobilidade no sentido de não haver lutas para mudanças nas políticas públicas e na cultura das instituições.

\section{CONSIDERAÇÕES FINAIS}

A investigação baseada nas rotinas familiares aliada aos instrumentos genograma e ecomapa permitiram melhor compreensão do cotidiano dos arranjos monoparentais, através da identificação do funcionamento interno da família, evidenciando sua estrutura e dinâmica familiar, as formas de organização, os papéis e as tarefas exercidas por seus membros. Também possibilitou identificar a complexidade das relações que se estabelecem nessas famílias, por meio das interações entre seus próprios membros e deles com o ambiente externo.

Retomando o objetivo deste estudo, que foi compreender o impacto da hospitalização infantil nas rotinas das famílias monoparentais, foi possível perceber que a dependência da rede de apoio familiar e a dificuldade de um olhar individualizado para as diferentes formas de família, por parte dos profissionais e das instituições para atender às suas demandas, são os principais fatores que causam o impacto nas rotinas diárias desses núcleos.

\section{REFERÊNCIAS}

1. Vitale MAF. Famílias monoparentais: indagações. Serviço Social \& Sociedade: Famílias. 2002;71(XXIII):45-62.

2. Brasil. Constituição (1988). Constituição da República Federativa do Brasil. Brasília, DF: Senado Federal; 1988.

3. Santos JB, Santos MSC. Família monoparental brasileira. Rev Jur Presidência 2009; 10(92):01-30.

4. Denham SA. Family Routines: a structural perspective for viewing family health. ANS Adv Nurs Sci. 2002;24(4):60-74. 5. Boehs AE, Grisotti M, D'Aquino MW. Routines in families with infants. Rev Latino-am Enfermagem. 2007;15(5):902-8.

6. Jorge CSG, Boehs AE, Fernandes GCM, Souza AIJ. Família de crianças desnutridas: rotinas diárias. Cienc Cuid Saude. 2009;
Os desafios e mudanças sobre o cotidiano das relações familiares acabam sendo absorvidos pelo profissional que trabalha com famílias. Portanto, as equipes de enfermagem e de saúde devem conhecer o conceito de família e examinar seus próprios valores com relação aos papéis familiares no cuidado, e especificamente sobre a naturalização do cuidado feminino. Dessa forma, os resultados desta pesquisa trazem alguns apontamentos que podem contribuir para que a prática profissional na atenção hospitalar se aproxime da realidade dessas famílias.

Portanto, a equipe de enfermagem deve olhar para a família de forma integral, pois assim poderá reconhecer as dificuldades que a hospitalização traz para o cotidiano.

Deve-se repensar o cuidar da criança hospitalizada, incluir um olhar e um agir ampliados para a família, tornando-a parte do plano de cuidado, pautado no respeito às singularidades, considerando o elo famíliacriança como um só cliente. Para isso também se torna necessária a revisão de normas e regras das instituições, as quais devem ser pautadas para atender as necessidades das rotinas destas famílias na atualidade. Desta forma, tais intervenções poderão contribuir para uma melhor adaptação do sistema familiar neste período de crise.

Por fim, deve-se explorar o cuidado de enfermagem à família monoparental em todos os níveis de atenção e nas diferentes fases do ciclo vital familiar. Estas pesquisas poderão permitir aos profissionais, especialmente aos de enfermagem, desenvolvimento de um olhar sensível e pormenorizado do dia a dia das famílias, fornecendo possibilidades para os profissionais identificarem de qual forma podem ajudar e/ou fortalecer este grupo familiar nas práticas produtoras de saúde e no enfrentamento das situações de doenças.

8(4):563-70.

7. Silva SSC, Pontes FAR, Santos TM, Maluschkr JB, Mendes LSA, Reis DC, et al. Rotinas familiares de ribeirinhos amazônicos: uma possibilidade de investigação. Psic: Teor e Pesq. 2010; 26(2):341-50.

8. Fernandes GCM, Boehs AE. Rotinas de cuidado em relação à saúde de famílias em transição após um desastre natural. Rev. Latino-Am. Enfermagem jul-ago. 2013;21(4):[08 telas]. 9. Faquinello $P$, Higarashi IH, Marcon SS. O atendimento humanizado em unidade pediátrica: percepção do acompanhante da criança hospitalizada. Texto contexto enferm. 2007;16(4):609-16.

10. Lima AS, Silva VKBA, Collet N, Reichert APS, Oliveira BRG. 
Relações estabelecidas pelas enfermeiras com a família durante a hospitalização infantil. Texto contexto - enferm.

2010;19(4):700-08.

11. Mello WA, Marcon SS, Uchiura TT. A hospitalização de crianças na perspective de seus acompanhantes. Rev Enfer UERJ. 2010; 18(4): 565-571.

12. Molina RCM, Fonseca EL, Waidman MAP, Marcon SS. A percepção da família sobre sua presença em uma unidade de terapia intensiva e neonatal.Rev Esc Enferm USP. 2009;43(3):630-8.

13. Montefusco SRA, Bachion MM, Nakatani AYK. Avaliação de famílias no contexto hospitalar: uma aproximação entre o modelo Calgary e a taxonomia da NANDA. Texto contexto enferm. 2008;17(1):72-80.

14. Morais GSN, Costa SFG. Experiência existencial de mães de crianças hospitalizadas em unidade de terapia intensiva pediátrica. Rev Esc Enferm USP. 2009;43(3):639-46.

15. Nascimento LC, Luiz FMR, Furquim PS, Bortoli PS, Rigotti AR, Gianoti S. A utilização do lazer como estratégia para integração de familiares/acompanhantes em enfermaria de pediatria. Esc Anna Nery R Enferm. 2006;10(3): 580-5.

16. Pinto JP, Ribeiro CA, Silva CV. Procurando manter o equilíbrio para atender suas demandas e cuidar da criança hospitalizada: a experiência da família. Rev Latino-Am Enfermagem. 2005;13(6):974-81.

17. Quirino DD, Collet N, Neves AFGB. Hospitalização infantil: concepções da enfermagem acerca da mãe acompanhante. Rev Gaúcha Enferm. 2010; 31(2):300-6.

18. Santos AMR, Amorim NMA, Braga CH, Lima FDM, Macedo EMA, Lima CF. Vivências de familiares de crianças internadas em um serviço de pronto-socorro. Rev Esc Enferm USP. 2011;

45(2):473-9.

19. Silveira AO, Angelo M, Martins SR. Doença e hospitalização da criança: identificando as habilidades da família. Rev Enferm UERJ. 2008;16(2):212-7.

20. Wright LM, Leahey M. Enfermeiras e famílias: um guia para avaliação e intervenção na família. $4^{\text {a }}$ ed. São Paulo: Roca; 2009. 21. Bauer MW, Gaskell G. Pesquisa qualitativa com texto, imagem e som: um manual prático. $7^{\text {a }}$ ed. São Paulo (SP): Vozes; 2008.

22. Boyce EWT, Jensen EW, James SA, Peacock JL. The Family Routines Inventory: theoretical origins. Soc Sci Med.

1983;17(4):193-200.

Artigo recebido em 24/07/2012.

Aprovado para publicação em 10/09/2013.

Artigo publicado em 31/12/2013. 